\title{
Assessment of Effects of Stress among Healthcare Providers at the Tabarka and Jendouba General Hospital's Emergency Service Units in Northern Tunisia
}

\author{
Neila Maaroufi' ${ }^{1}$ Jalel Rzeigui², Lotfi Ayari' ${ }^{1}$, Zeineb Abid'1, Mahassen Dhaouadi', \\ Hadda Saidi ${ }^{1}$ \\ ${ }^{1}$ Emergency Service, General Hospital of Jendouba, Jendouba, Tunisia \\ ${ }^{2}$ Emergency Service, General Hospital of Tabarka, Tabarka, Tunisia \\ Email: maaroufineila@yahoo.fr
}

Received 4 May 2015; accepted 1 August 2015; published 4 August 2015

Copyright (C) 2015 by authors and Scientific Research Publishing Inc. This work is licensed under the Creative Commons Attribution International License (CC BY). http://creativecommons.org/licenses/by/4.0/

(c) (i) Open Access

\begin{abstract}
The study assessed the relationship between exposure to stress and posttraumatic symptoms among nurses and physicians in a Jendouba general hospital. Hospital staff who were exposed to stress were assessed for posttraumatic stress disorder. High levels of stress symptoms were found in physicians and nurses. Logistic regression analysis showed that nurses had an increased risk for posttraumatic stress disorder factors characterized by negative behavior to patient, increased workload excessive ambiguity and role conflict and the lack of free. These findings showed that nurses suffered from more severe posttraumatic symptoms compared to physicians after exposure to prolonged stress. The gap between physicians and nurses warrants further study.
\end{abstract}

Keywords

Stress, Hospital Personnel, Nursing, Depressive Symptoms, Workload

\section{Introduction}

As is well known, chronic stress is an important negative predictor of human health, and could result in some stress-related illnesses including the burnout. This symptom is an important phenomenon that derives from chronic emotional responses and interpersonal stressors that occur at work, and burnout syndrome is determined by the dimensions of emotional exhaustion, cynicism, and reduced professional efficacy [1]. According to Mas- 
lach, burnout has three dimensions including "emotional exhaustion” where the emotional reserves are depleted and employees feel that they are no longer able to provide good quality work. They usually have feelings of extreme energy loss and a sense of being completely drained out of emotional and physical strength [2]. The second dimension involves "depersonalization" which is defined as the development of negative attitudes, such as cynicism and negativism, both in thinking as well as in behavior, in which co-workers and service recipients are approached with derogatory prejudices and treated accordingly [2]. The third aspect involves "lack of personal accomplishment" which is defined as lack of feelings regarding both job and personal competence and failure in achieving goals [3]. There is a general consensus in the literature that emotional exhaustion is the central or core dimension of burnout [3]. The consequences of burnout are multiple. Apart from a decrease in the quality of care (in case of health care jobs), a relationship was found between burnout and the occurrence of musculoskeletal disorders, depression, obesity, insomnia, alcohol intake and drug abuse. Burnout also has a negative impact on the quality of life of the employee, with more intra-relational conflicts and aggression [4]. Finally, burnout can also lead to a significant economic loss through increased absenteeism, higher turnover rates and a rise in health care costs [5]. The prevalence of burnout, assessed by use of a self-report instrument in a general working population in Western countries, has been reported to range from $13 \%$ to $27 \%$ [6] with nurses and doctors at higher risk [2].

Emergency (ER) nursing is a specialty that differs from other nursing specialties: work in emergency departments is hectic, unpredictable and constantly changing. ER-nurses are confronted with a very broad range of diseases, injuries and problems.

The study examined the relationship between exposure to stress and posttraumatic symptoms among nurses and physicians in a general hospital.

\section{Materials and Methods}

An inquiry was conducted among 120 doctors and nurses working in emergency services from two emergency departments at two hospitals including Tabarka and Jendouba in Northern Tunisia.

All doctors and nurses who work in both services were included. Members in leave during the study were excluded. We also excluded the workers and staff juxtamedical. Consent was obtained from participants.

A set of questionnaires was administered to obtain socio-demographic and occupational information. The following variables were assessed: age, gender, marital status (married, separated or divorced, unmarried, and widowed), number of children (no children, one child, two children, and three or more children), the level of healthcare (primary vs. hospital healthcare), healthcare service areas (surgical healthcare, medical attention healthcare, maternal and infant healthcare, emergency and critical healthcare, and community healthcare), job shift (rotating, morning shift, afternoon shift, and night shift), on-call requirement (yes vs. no), administrative tasks in their occupational area (yes vs. no), seniority in the current job and seniority in the profession. Burnout syndrome was measured using the Maslach Burnout Inventory (MBI) [2]. It comprises of 22 items with a sevenpoint Likert response scale from zero ("never") to six ("every day"). The MBI has three dimensions including emotional exhaustion (EE; nine items), depersonalization (D; five items) and personal accomplishment (PA; eight items). For emotional exhaustion, the cut-off point for a high level was $>24$; for depersonalization, it was $>9$; and for personal accomplishment, it was $<33$. Therefore, high scores for emotional exhaustion and depersonalization, and low scores for personal accomplishment were regarded as indicative of burnout.

Beside, individual impressions were analyzed in order to measure level of stress. Data obtained from the study was analyzed using the SPSS statistical software package 20 for Windows and student-t test was used to compare the means. The $p$ value $(p<0.05)$ was considered statistically significant. Analysis descriptive statistics including medians and range are presented for working conditions, job strain, work engagement, burn out and negative work-home interactions. Pearson's correlation coefficient was performed between these outcome variables. According to standardized scores, the four first outcome variables are categorized in small, medium or high level of score.

\section{Results}

One hundred and twenty questionnaires were distributed, 100 were collected and analyzed. The overall participation rate was $83 \%$. The mean age of the study population was 36.5 years ( \pm 8.2 years). The participants were predominantly female with a sex ratio (male/female) of 0.75 . Of these about $54 \%$ were married and $43 \%$ were 
single. Three percent were divorced. The majority of the participants (72.9\%) lived in urban areas. And about 30\% had more than two children. Ten percent were hypertensive, Three percent were diabetics and one percent had a history of heart pathology. Eight percent were alcoholics of which three percent were experiencing alcoholism. Eighty percent of the participants were nurses and Twenty percent were physicians. The majority (86\%) practice the guard.

A proportion of 37\% worked more than 40 hours per week. On the professionally, the choice of profession was deliberate in $68.3 \%$ of cases. And $92.3 \%$ reported having a good relationship with their superiors.

More than half of the participants (56\%) were affected by burnout of which $47 \%$ had high levels of emotional exhaustion, 36.6\%had a high level of depersonalization and 33\% had a level Low professional accomplishment. The burnout syndrome was more marked among nurses with achievement of three dimensions: A level high emotional exhaustion (43\%), a high level of depersonalization (38\%) and a low level of professional achievement (24\%) and for the physicians, there was a breach of a single dimension. The excessive workload was the major cause of the depletion of the professionals for about three-quarters (71\%) while fatigue was the result of exhaustion most mentioned by the participants (88\%).

Among socio-demographic factors, female sex $(p=0.02)$ and age less than 50 years $(p=0.03)$ were associated with a high score emotional exhaustion. For other dimensions of burnout found no link with the sociodemographic parameters. High score emotional exhaustion was associated with the number of working hours less than 40 hours/week and seniority less than 10 years. The practice care was associated with the different dimensions of burnout.

Among the causes of burnout, ambiguity and role conflict were associated with high levels of emotional exhaustion and depersonalization. Furthermore, it was noted that subjects with suicidal ideation had a level of burnout high regarding the physical signs, emotional exhaustion was associated with multiple somatic complaints.

Factors correlated with burnout included negative behavior to patient (OR: 2.52, 95\% CI [1.16 to 5.20], ( $p<$ $0.01)$, a workload excessive ( $\mathrm{OR}=3.80 ; 95 \% \mathrm{CI}=[1.079$ to 13.420$] ; p=0.038)$, ambiguity and role conflict $(\mathrm{OR}=3.52 ; 95 \% \mathrm{CI}=[3.52-10.50], p=0.02)$ and the lack of free time $(\mathrm{OR}=3.54 ; 95 \% \mathrm{CI}=[3$ to 8.13$], p=$ 0.03). Furthermore, the predictors of level Low performance requirements were medical malpractice $(\mathrm{OR}=$ $3.35 .95 \%$ CI $[1.07$ to 10.6$] ; p=0.038$ ) and incidents involving patient's companions (OR $=3.6$; $\mathrm{CI}=95 \%$ [1.14 - 12.12], $p=0.02$ ) (Table 1).

\section{Discussion}

This study revealed the presence of burnout in the three dimensions of emotional exhaustion, depersonalization and reduced personal accomplishment as well as signs of psychological distress and low levels of job satisfaction. This finding was in line with previous reports which have indicated that burnout can affect work outcomes [7]. Burn-out is a reality in the emergency services. And in present study, the results showed that the prevalence of burnout was $56 \%$ and this correlated well with what has been reported in literature ranging from $5 \%$ to $50 \%$ [8]. This variability in results could be explained by methodological differences and socio-occupational populations studied (culture, lifestyle, working hours, marital status.)

Previous studies in Tunisian about burnout on a population of 60 nurses in hospitals in Sousse and Monastir, it showed that $81.7 \%$ of surveyed nurses had high emotional exhaustion and $70 \%$ had a high level of depersonalization. The fulfillment staff was low in $16.7 \%$ of nurses [9]. Previous studies on nurses in Canada, the US and England, showed that $38.3 \%$ to $48.1 \%$ of nurses had reported being dissatisfied at work, and $32.9 \%$ to $54.2 \%$ had a burn-out [10].

Female gender was correlated with a high score of exhaustion emotional. Several studies have confirmed this relationship [11]. This greater vulnerability of women could be related to a greater involvement in the emotional relationship towards their sick and struggling to balance their professional lives and family [10]. Other studies

Table 1. Factors correlated with burnout.

\begin{tabular}{|c|c|c|c|}
\hline & OR & $95 \% \mathrm{CI}$ & $p$ \\
\hline Negative behavior to patients & 3.80 & {$[1.079-13.420]$} & 0.038 \\
\hline Ambiguity and role conflict & 3.52 & {$[3.52-10.50]$} & 0.02 \\
\hline lack of free time & 3.54 & [3 - 8.13] & 0.03 \\
\hline
\end{tabular}


attributed this to the psychobiological characteristics of women who have attitudes of more emotional and empathetic unlike men who rather more instrumental attitudes [12].

The results of the previous studies are subjects of controversy. Catts et al. [13] found a male association of burnout as compared to females.

They complained of the greater work load given to sex masculine. The Kovacs team found a correlation between depersonalization and male sex [14]. The teams Poncet, Di Iorio and Raggio (2010) have found that Women were more affected by this syndrome [15]. Multivariate analysis of the present study demonstrated that female gender was protective of depersonalization [13]. According to previous studies, age less than 50 years, seniority less than 10 years were correlated with high level of burnout [14].

The duration of professional practice, correlated to burnout in the present study, though still subject of controversy. Indeed, several previous studies reported that Burnout was negatively related to work experience [15]. Among the occupational characteristics, the number of guards correlated with burnout. Obviously, sleep disorders and disruption of the biological clock generated by the guards have been reported to cause depressive symptoms [13].

In addition, the workload was the most reported cause to explain burnout. Moreover, many surveys have shown that excessive working hours not necessarily lead to an increase productivity. They would tend to reduce the effectiveness and the efficiency of individuals [5].

In the present study, depression was not evaluated by ladders specific, however, and among the perceived consequences, the feeling of worthlessness and suicidal ideation were correlated with burnout. And indeed, the confusion between burnout and depression are reported to be common [2].

Study limitations: Most studies on burnout are subject to the limitations inherent in survey studies. The present study was no exception. The study population consisted of a self-selected group. It was possible that individuals with high levels of burnout would be less likely to participate to this study or that individuals with high levels of burnout would be more likely to participate in a burnout assessment. Further, the present survey instrument used involved self-reports of attitudes being measured at a single point in time. It was possible that substantial variations in the level of burnout may occur in individuals over time. Finally, as with all crosssectional studies, no clear determination of cause and effect could be made. Thus, it was not evident at this time whether high levels of burnout accounted for result from the unhealthful personal habits and the negative perceptions of self and work found in certain segments of our study population. A longitudinal study would have to follow Change Burnout over time.

\section{Conclusions}

All these findings in the present study contributed to the understanding of the relationship between stress and burnout, and verified the fact that resilience is a kind of positive personality trait for combating burnout. Additionally, these findings supported the transactional model of stress and coping theory.

This study has identified healthcare providers, at the Tabarka and Jendouba General Hospitals' emergency service, working conditions and has measured their levels of burn out, job strain, work engagement and negative work-home interaction with validated questionnaires. They had several adequate job resources and experienced a very high work engagement. However, some problems appeared in the control over time management and in the social support for which organizational solutions could be proposed.

Healthcare professionals with lower annual income, younger age, and fewer years of experience reported higher levels of stress and burnout. With evidence that high levels of staff stress are associated with decreased patient satisfaction and high staff turnover rates, it is important that clinicians and policy makers take proactive steps to develop programs aimed at reducing stress and burnout for healthcare professionals. These programs are likely to also increase the well-being of healthcare professionals and improve the quality of mental health services in emergency services.

\section{Acknowledgements}

The contribution of all healthcare professionals who completed the survey is gratefully acknowledged.

\section{Contributors}

All authors confirm that the content of this paper has not been published or submitted for publication elsewhere 
except as a brief abstract in the proceedings of a scientific meeting.

All authors have contributed significantly and all authors are in agreement with the content of the manuscript.

\section{Conflict of Interest}

Statement All Authors declares that there is no conflict of interest in this research. All authors confirm that there are no financial and personal relationships with other propel or organizations that could inappropriately influence this research.

\section{References}

[1] Hao, S.W., Hong, W., Xu, H.H., Zhou, L.L. and Xie, Z.Y. (2015) Relationship between Resilience, Stress and Burnout among Civil Servants in Beijing, China: Mediating and Moderating Effect Analysis. Personality and Individual Differences, 83, 65-71. http://dx.doi.org/10.1016/j.paid.2015.03.048

[2] Maslach, C. (1976) Burn-Out. Human Behavior, 5, 16-22.

[3] Freudenberger, H.J. (1977) Burnout: The Organizational Menace. Training and Development Journal, 31, $26-27$.

[4] Gaines, J. and Jermier, J. (1983) Emotional Exhaustion in a High Stress Organization. Academy of Management Journal, 26, 567-586. http://dx.doi.org/10.2307/255907

[5] Wu, S., Li, H., Wang, X., Yang, S. and Qiu, H. (2011) A Comparison of the Effect of Work Stress on Burnout and Quality of Life between Female Nurses and Female Doctors. Archives of Environmental \& Occupational Health, 66, 193-200. http://dx.doi.org/10.1080/19338244.2010.539639

[6] Borritz, M., Rugulies, R., Christensen, K., Villadsen, E. and Kristensen, T. (2006) Burnout as a Predictor of SelfReported Sickness Absence among Human Service Workers: Prospective Findings from Three Year Follow up of the PUMA Study. Occupational and Environmental Medicine, 63, 98-106. http://dx.doi.org/10.1136/oem.2004.019364

[7] Kant, I., Jansen, N., Van Amelsfoort, L., Mohren, D. and Swaen, G. (2004) Burnout among the Working Population. Results of the Maastricht Cohort Study. Gedrag en Organisatie, 17, 5-17.

[8] Kalemoglu, M. and Keskin, O. (2002) Evaluation of Stress Factors and Burnout in the Emergency Department [In Turkish]. Ulus Travma Derg, 8, 215-219.

[9] Amamou, B., Bannour, A., Ben Hadj Yahia, M., Ben Nasr, S. and Ben Hadj Ali, B. (2014) Haute prévalence du Burnout dans les unités Tunisiennes prenant en charge des patients en fin de vie. The Pan African Medical Journal, 19, 9. http://dx.doi.org/10.11604/pamj.2014.19.9.2865

[10] Aiken, L.H., Clarke, S.P., Sloane, D.M., Sochalski, J. and Silber, J.H. (2002) Hospital Nurses Taffing and Patient Mortality, Nurse Burnout, and Job Dissatisfaction. JAMA, 288, 1987-1993. http://dx.doi.org/10.1001/jama.288.16.1987

[11] Bonneterre, V., Jolivet, A. and Lang, S. (2010) Evaluation des contraintes psychologiques et organisationnelles (CPO) chez les soignants: Cohorte ORSOSA et applications. Archives des Maladies Professionnelles et de l'Environnement, 71, 489-492. http://dx.doi.org/10.1016/j.admp.2010.03.079

[12] Cebrià, J., Soberqués, J., Bodriguez, C. and Segura, J. (2003) Influence of Burnout on Pharmaceutical Expediture among Primary Care Physicians. Gac Sanit, 17, 483. http://dx.doi.org/10.1016/S0213-9111(03)71795-6

[13] Pereira, S.M., Fonseca, A.M. and Carvalho, A.S. (2011) Burnout in Palliative Care: A Systematic Review. Nursing Ethics, 18, 317-326. http://dx.doi.org/10.1177/0969733011398092

[14] Klersy, C., Callegari, A., Martinelli, V., Vizzardi, V., Navino, C., Malberti, F., et al. (2007) Burnout in Health Care Providers of Dialysis Service in Northern Italy-A Multicentre Study. Nephrology Dialysis Transplantation, 22, 2283-2290. http://dx.doi.org/10.1093/ndt/gfm111

[15] Popa, F., Raed, A., Purcarea, V.L., Lal, A. and Bobirnac, G. (2010) Occupational Burnout Levels in Emergency Medicine: A Nationwide Study and Analysis. Journal of Medicine and Life, 3, 207-215. 